\title{
Quality improvement, different roads to Rome
}

\author{
A. J. J. C. Bogers
}

Published online: 20 July 2011

(C) The Author(s) 2011. This article is published with open access at Springerlink.com

Algra and co-authors [1] can be congratulated on both their results in the treatment of the hypoplastic left heart syndrome and on their efforts in continuous improvement of quality of care.

The Norwood operation for the hypoplastic left heart syndrome has already attracted quite some attention in the Netherlands over time, as demonstrated by previous publications, concerning the introduction and the consolidation of this approach, respectively [2, 3]. The team from the Wilhelmina Children's Hospital now takes another step by not only providing excellent results but also addressing the problem of interstage mortality.

The good outcome is achieved despite the limited number of patients, which did not allow for a randomised comparison of the arterio-pulmonary shunt with the ventriculo-pulmonary shunt. This ventriculo-pulmonary shunt in the Norwood procedure has been introduced to improve the overall results and not as a specific solution for patients with a recognised risk factor. These patients will, of course, benefit as well but the confidence limits of the findings must be kept in mind. Nevertheless, results achieved by dedication on top of cumulative findings in the literature are equally beneficial for the patient.

In this regard Algra and co-authors do not provide data on the analysis of the patients who were not completely haemodynamically stable after the neonatal Norwood procedure. Not infrequently, the literature has shown suboptimal shunt functioning, even after perfect initial construction. This might be due to patient growth, resulting in stretching or distortion of the shunt. In that situation either early execution of the next stage or interstage repair can be considered. The concentration should be on critical

A. J. J. C. Bogers $(\bowtie)$

Department of Cardiothoracic Surgery, Erasmus MC,

Rotterdam, the Netherlands

e-mail: a.j.j.c.bogers@erasmusmc.nl follow-up of the patient and does not necessarily involve prolonged hospitalisation. Data from other centres show comparable improvement of results without a prolonged hospital stay. Interstage mortality might be reduced in one way or the other, but will prove not to be eliminated.

In addition, the question can be raised whether the wellrecognised risk factors for the neonatal Norwood procedure $[1,4]$ might also be approached by the so-called hybrid strategy with bilateral pulmonary arterial banding and keeping the arterial duct open with prolonged prostaglandin infusion or ductal stenting for systemic circulation. Such a limited surgical/interventional procedure is a much more simple procedure and claims to carry less risk, while equally providing the opportunity for further surgical steps beyond the neonatal age [5].

Unfortunately, no randomised studies in this regard seem to be feasible and the development of knowledge depends on registries and data from dedicated centres. The four certified centres for congenital heart disease in the Netherlands have started a quality program including site visitations and benchmarking of data. Perhaps this will provide a platform for acceleration of generation of knowledge from the practical data from each centre. This will improve the quality of care and will be beneficial for the individual patient.

Open Access This article is distributed under the terms of the Creative Commons Attribution Noncommercial License which permits any noncommercial use, distribution, and reproduction in any medium, provided the original author(s) and source are credited.

\section{References}

1. Algra SO, Breur JM, Evens FC, et al. Improving surgical outcome following the Norwood procedure. Neth Heart J. 2011. doi 10.1007/ s12471-011-0171-8 
2. Bogers AJJC, Frohn-Mulder IME, Witsenburg M, et al. Initial experience with the Norwood procedure for aortic atresia in the hypoplastic left heart. Cardiovasc Eng. 1998;3:67-70.

3. Hazekamp MG, Rijlaarsdam ME, Schoof PH, et al. Favourable results with surgical treatment in 43 children with hypoplastic leftheart syndrome or similar disorders, 1999-2005. Ned Tijdschr Geneeskd. 2006;150:1930-5.
4. Stasik CN, Gelehrter S, Goldberg CS, et al. Current outcomes and risk factors for the Norwood procedure. J Thorac Cardiovasc Surg. 2006;131:412-7.

5. Akintürk H, Michel-Behnke I, Valeske K, et al. Hybrid transcatheter-surgical palliation: basis for univentricular or biventricular repair: the Giessen experience. Pediatr Cardiol. 2007;28:79-87. 